\title{
Effect of impervious surface area and vegetation changes on mean surface temperature over Tshwane metropolis, Gauteng Province, South Africa.
}

\author{
Adeniyi Adeyemi ${ }^{1}$, Joel Botai ${ }^{1,3}$, Abel Ramoelo $^{2}$, Fritz van der Merwe ${ }_{2}{ }_{2}$ Philemon Tsela $^{1}$ \\ ${ }^{1}$ Department of Geography, Geoinformatics and Meteorology, University of Pretoria, Pretoria, \\ South Africa; E-mail: adedayoadeyemi01@gmail.com \\ ${ }^{2}$ Natural Resources and Environment Council for Scientific and Industrial Research, Pretoria, \\ South Africa \\ ${ }^{3}$ South African Weather Service, Pretoria, South Africa
}

DOI: http://dx.doi.org/10.4314/sajg.v4i4.1

\begin{abstract}
The Tshwane Metropolis, Gauteng Province, South Africa, continues to experience rapid urbanization as a result of population growth. This has led to the conversion of natural lands into large man-made landscapes i.e., increase in impervious surfaces and a decrease in vegetative cover. This land use or land cover changes are also thought to affect the climate of the Tshwane metropolis as is evidenced by heat waves in 2013 and 2014. This paper describes how vegetation and impervious surface area (ISA) or built up areas were classified from Landsat 8 LCDM, 2013, and Landsat 7 ETM+, 2003 images using thematic spectral indices and mean surface temperatures derived from the thermal bands. The linear relationship between the two land cover types and surface temperature (LST) derived from the thermal bands was also examined. The results of this research reveal that the ISA increase has occurred due to urban sprawl and this has contributed to increase in surface temperature.
\end{abstract}

Keyword: Thematic indices, surface temperature, Landsat, vegetation, ISA, Tshwane Metropolis.

\section{Introduction}

Globally, rapid increase in population in major cities has led to urban sprawl at an unprecedented rate which is, according to the analysis and predictions of the United Nations report (2012), expected to continue into the next epoch (Deng and Wu (2013). Moreover, Parece and Cambel (2013) reflected that over $50 \%$ of the global population lives in urban settlements and the United Nations (2009) estimate that it will increase to $69 \%$ by 2050 . The highest rate of urbanization and associated land use or land cover changes are anticipated in developing countries (Montgomery and Hewett, 2005). Over the last decades, Southern Africa has been facing major land use and land 
cover changes, such as loss of natural land, i.e. forest or plantations, agricultural lands and grasslands coupled with growing impervious surfaces such as roads, sidewalks, parking lots, rooftops and bare lands due to a continuous increase in the population. Brunsell (2006) reported that the conversion of natural land to impervious surfaces is one of the main contributors to climate change and variability in different parts of the world.

Land surface temperature (LST) is measured by the surface energy balance, atmospheric state and thermal properties of the surface. Zhang et al. (2009) asserted that it is the alteration of the land surface which influences changes in the thermal properties of the urban landscape, making it warmer than the surrounding rural areas and creating urban heat islands. Therefore monitoring land cover dynamics in the urban area, in a timely and cost effective manner, is very important for local communities and decision makers. It enables them to plan, manage and conserve natural resources and the environment.

Remote sensing data offers considerable measurement possibilities (e.g. spectral, spatial and temporal) combined with timely data acquisition and wide area coverage. Due to these features, it has been used to separate different land cover types for the last few decades (Xu, 2007). Improved data over the years have led to a wide variety of infrared thermal sensors such as NOAA-AVHRR, MODIS, ASTER and Landsat TM/ETM+, being used for the estimation of land surface temperatures, temperature variability and urban heat islands (Pinheiro, 2006; Ifatemehin et al., 2009; Jeong, 2012).In-situ data from meteorological stations, though they have a high temporal resolution and offers long term coverage, lack spatial information (area covered) when compared to remote sensing data (Weng, 2009).

Even though there is an increasing concern regarding global climate change and a greater availability of remote sensing data as mentioned above, few studies on the effect of land use or land cover changes on surface temperature have been conducted in major cities in Africa. In this study, impervious surface area and vegetation are extracted using thematic oriented indices. Thermal bands from Landsat 7 ETM+ and Landsat 8 LCDM are analyzed to derive the mean surface temperature for the two land cover classes on the particular two days of different years.

\section{Data and methodology}

\subsection{Study area and data}

Geographically the Tshwane Metropolitan Municipality (TMM) stretches from $25^{\circ} 19.5^{\prime}$ South to $25^{\circ} 56.3^{\prime}$ 'South and from $27^{\circ} 53.25^{\prime}$ East to $28^{\circ} 27.3^{\prime}$ East. It is located in the North-East of Gauteng Province, South Africa. The TMM has a land area of $2198 \mathrm{~km}^{2}$ and lies at an altitude of 
about 1,350m (4,500ft.) above sea level. The climate varies between hot, arid steppe in the north to warm, temperate with dry winters and warm summers in the south (Conradie, 2012). According to Goddard Institute of Space Studies (2008), Tshwane has an average annual temperature of $18.7^{\circ} \mathrm{C}$, which is high considering its high altitude of about $1350 \mathrm{~m}$. Rain is predominantly in the summer months with an average annual precipitation of $715 \mathrm{~mm}$. The driest and wettest months are June and January with average precipitations of $6 \mathrm{~mm}$ and $122 \mathrm{~mm}$ respectively. In the past decades, TMM has experienced a constant growth in population and expansion of the metropolis. The estimated population has increased to about 2.950 million after the 2011 amalgamation of the Metsweding District Municipality (City of Tshwane Metropolitan Municipality, 2011). This sprawl has generated various urban land uses such as residential, commercial and industrial and has continuously necessitated the construction of new impervious surface areas thereby replacing natural vegetation.

In this study, two multi - date images recorded by Landsat 7 ETM+ and Landsat 8 LCDM were downloaded from http://www.glovis.usgs.gov for the dates 31/03/2003 and 13/11/2013 for Tshwane Metropolitan respectively (Table 1). The study mainly relied on a land use map with a scale of 1:10,000 and a polygon shape file (Projection: Universal Transverse Mercator (UTM) zone 35 South, Datum: WGS 1984) of Tshwane metropolis to clip the study area. Software employed for desktop analysis are ArcGIS 10.1, ENVI, QGIS and STATISTICA. Reference temperature data were also acquired from the South African Weather Stations.

Data pre-processing is an important phase of satellite imagery processing and analysis, because it has an impact on all other actions and the final product quality. Image-to-image registration was carried out using ENVI by selecting 20 ground control points (GCPs) using a first order polynomial transformation technique. Total root mean square (RMS) error of 0.46 pixel associated with the GCPs was accepted. 


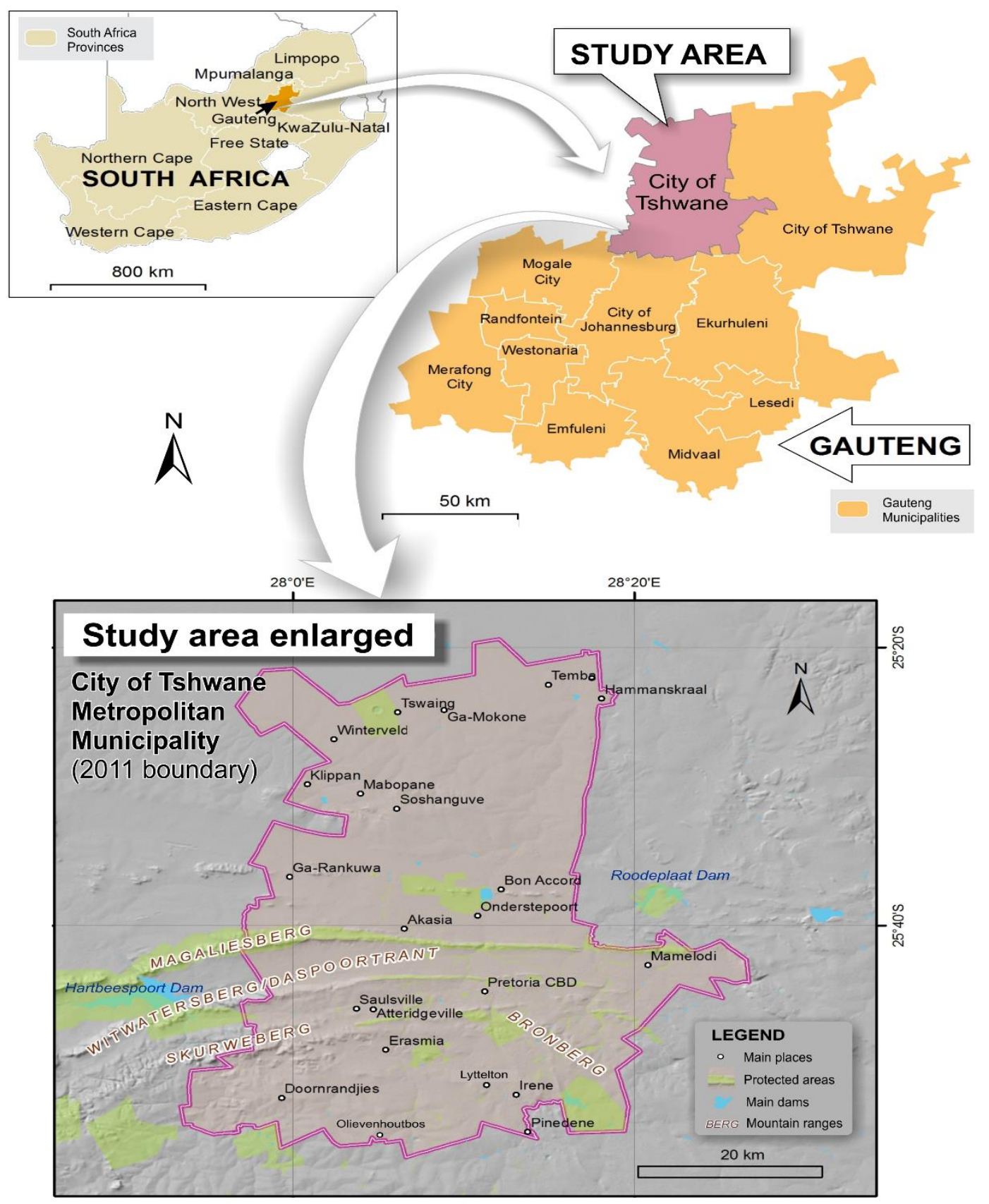

Figure 1. Map showing the location Tshwane metropolitan municipality within the Gauteng Province in South Africa.

Table1. Landsat scenes accessed for the study

\begin{tabular}{cccccc}
\hline Year & Sensor & Path & Row & $\begin{array}{c}\text { Date } \\
\text { acquired }\end{array}$ & $\begin{array}{c}\text { Resolution } \\
(\mathbf{m})\end{array}$ \\
\hline 2003 & ETM+ & 170 & 078 & $2003 / 03 / 31$ & 30 \\
2013 & LDCM & 170 & 078 & $2013 / 11 / 13$ & 30 \\
\hline
\end{tabular}


During radiometric calibration, pixel values from raw, unprocessed bands for the Landsat images used were converted to spectral radiance and reflectance using equations given in Chander et al. (2009) and Landsat 8 handbook, 2013 to reduce noise so as to facilitate effective mapping (Kasischke et al., 2004).

\subsection{Image processing}

Image classification was carried out by assigning a land cover class to each pixel of the image, based on its spectral characteristics. This was achieved thresholding Normalized difference vegetation index (NDVI) and Normalized difference built up index (NDBI). Although there various vegetation indices in remote sensing of vegetation, NDVI was considered for this study because it takes the advantage of high vegetation reflectance NIR spectral ranges (Leprieur et al., 2000, Jensen, 2000; Xu,2010). NDVI is a ratio of the difference and summation of bands 4 and 3 (equation 1) respectively, and provides a value that range between -1.0 and +1.0 , where the positive values would normally indicate the presence of vegetated areas whereas, for negative values would be non-vegetated areas (Rouse et al., 1974). The formulae of NDVI is as follows;

$$
N D V I=\frac{N I R-R E D}{N I R+R E D}
$$

NDBI generated from the Landsat 7 ETM+ and Landsat 8 LCDM for the TMM revealed that the spectral response of built-up lands showed a higher reflectance in the mid infra-red (MIR) wavelength range than in the near infra-red (NIR). The mathematical expression for NDBI is given in equation 2 (Zha et al., 2003).

$$
N D B I=\frac{M I R-N I R}{M I R+N I R}
$$

In general, spectral index values vary across land cover types in different regions with dissimilar climatic and environmental conditions (Cheng et al., 2006). Also, spectral index such as NDVI suffer from a number of limitations that include value saturation and sensitivity to soil background among others according to Huete (1987).

Therefore, in the current study, appropriate threshold was performed to identification of spectral characteristics of different land cover types. Subsequently, the Landsat-derived NDVI images were labeled 'vegetation' for pixels having positive values and 'others' for all remaining pixels of negative value. In the NDBI binary image, built up or impervious surface area showed pixels with positive values while pixels with negative values were re-coded as 'others'. Through the arithmetic manipulation of red, near infrared and middle infrared bands of the Landsat images and recoding, it 
was possible to classify impervious surface area and vegetation within the study area using ArcGIS 10.1. Thereafter, each index derived image was reclassified and converted to polygons and exported as a shape file.

\subsection{Conversion to At-Satellite Brightness Temperature}

For Landsat thermal bands, the conversion of DN to At-Satellite Brightness Temperature in ENVI 5.1 classic is given by (https://landsat.usgs.gov/Landsat8_Using_Product.php).

$$
T_{b}=\frac{K_{2}}{\ln \left(\mathrm{K}_{1} / \mathrm{L}_{\lambda}\right)+1}
$$

Where: $\mathrm{K}_{1}=$ Band-specific thermal conversion constant (in watts/meter squared $*$ ster $* \mu \mathrm{m}$ ), $\mathrm{K}_{2}=$ Band-specific thermal conversion constant (in kelvin), $L_{\lambda}$ is the Spectral Radiance at the sensor's aperture, measured in watts/ (meter squared $*$ ster $* \mu \mathrm{m})$.

Table 2. The $K_{1}$ and $K_{2}$ constant for Landsat sensors are provided in the image metadata file.

\begin{tabular}{|l|l|l|}
\hline & Landsat 7 ETM + & Landsat 8 LCDM \\
\hline $\begin{array}{l}K_{l}(\text { watts/meter squared * ster } \\
\mu \mathrm{m})\end{array}$ & 666.09 & 774.89 \\
\hline$K_{2}($ Kelvin $)$ & 1282.71 & 1321.08 \\
\hline
\end{tabular}

\subsubsection{Conversion from brightness temperature to Land Surface Temperature (LST)}

After the image classification of the study area in Landsat 7ETM + and Landsat 8, the land surface emissivity values from literature of Mallick et al. (2008) was used to derive the surface temperature image. Thereafter, the emissivity raster images for the two years were generated and used in the conversion of brightness temperature image to Land Surface Temperature (LST) using the equation [4];

$$
L S T_{(\mathrm{KELVIN})}=\frac{T_{b}}{1+\left(\lambda+T_{b} / \rho\right) * \ln \varepsilon}
$$

To convert the LST image to Celsius image using the equation [5] below;

$$
L S T_{(\mathrm{CELSIUS})}=L S T_{(\mathrm{KELVIN})}-273.15
$$


Where: $\lambda$ is the wavelength of radiation emitted in Landsat $7 \mathrm{ETM}+(11.5 \mu \mathrm{m})$ and Landsat 8 $\operatorname{LCDM}(10.8 \mu \mathrm{m}) . \rho=\mathrm{h} * \mathrm{c} / \sigma, \sigma=$ Stefan Boltzmann's constant $\left(5.67 \mathrm{x} 10^{-8} \mathrm{Wm}^{-2} \mathrm{k}^{-4}\right), \mathrm{h}=$ Plank's constant $\left(6.626 \times 10^{-34} \mathrm{~J} \mathrm{sec}\right), \mathrm{C}=$ velocity of light, $\left.2.998 \times 10^{8} \mathrm{~m} / \mathrm{s}\right), \varepsilon=$ spectral emissivity coefficient (0.95).

\subsection{Statistical analysis}

Two statistical analysis techniques were applied to understand the influence of vegetation and builtup areas (ISA) on LST. Firstly, the NDVI and NDBI were reclassified in to low, medium and high, representing various magnitudes of the vegetation and built-up densities. Secondly, the two-way analysis of variance was implemented to test the significance difference of LST in various classes as derived above at a confidence level of $95 \%, \mathrm{p}<0.05$. Finally, the correlation analysis was done to test the relationship between LST and NDVI as well as NDBI respectively at the $95 \%$ confidence level $(\mathrm{p}<0.05)$.

\subsection{Results}

The binary images were generated using the raster calculator algorithm in spatial analyst tool of Arc GIS 10.1 raster software. The derived images for the two selected years are presented in Table 3 Landsat 7 ETM+ 2003 and Landsat 8 LDCM 2013 showing NDVI ranging from $-0.627-0.588$ and $-0.325-0.654$ and a NDBI ranging from $-0.735-0.700$ and $-0.539-0.599$ respectively (Table 3).

Table 3. Dynamic ranges of NDVI and NDBI of the Landsat images

\begin{tabular}{|c|c|c|c|c|c|c|}
\hline Index & \multicolumn{3}{|c|}{ Landsat 7ETM+ 2003 } & \multicolumn{3}{c|}{ Landsat 8LCDM 2013 } \\
\hline & Minimum & Maximum & Dynamic range & Minimum & Maximum & Dynamic range \\
\hline NDVI & -0.627 & 0.588 & 1.215 & -0.325 & 0.654 & 0.979 \\
\hline NDBI & -0.735 & 0.7 & 1.435 & -0.539 & 0.599 & 1.138 \\
\hline
\end{tabular}




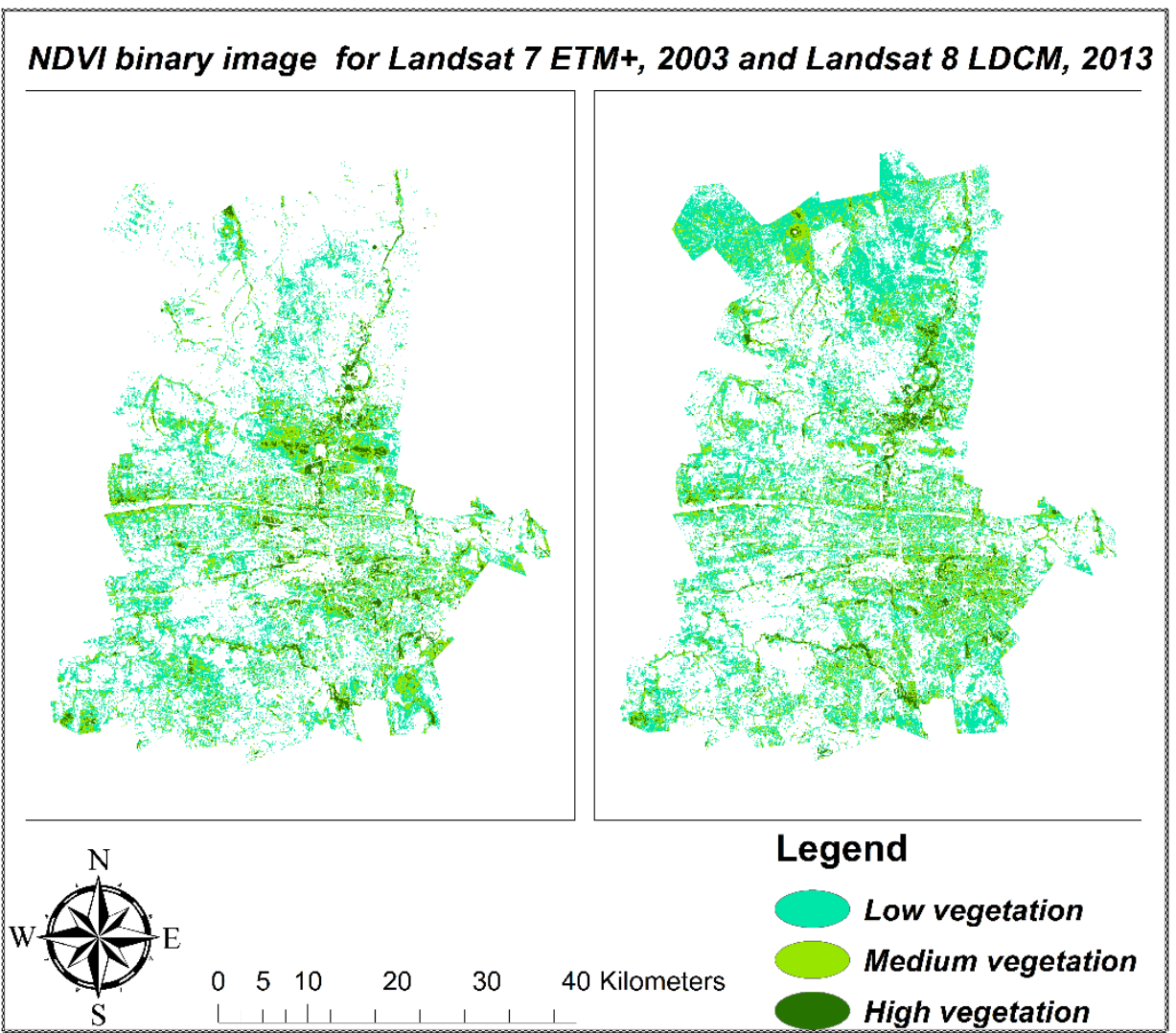

Figure 2. NDVI binary image for Landsat 7 ETM+ \& Landsat 8

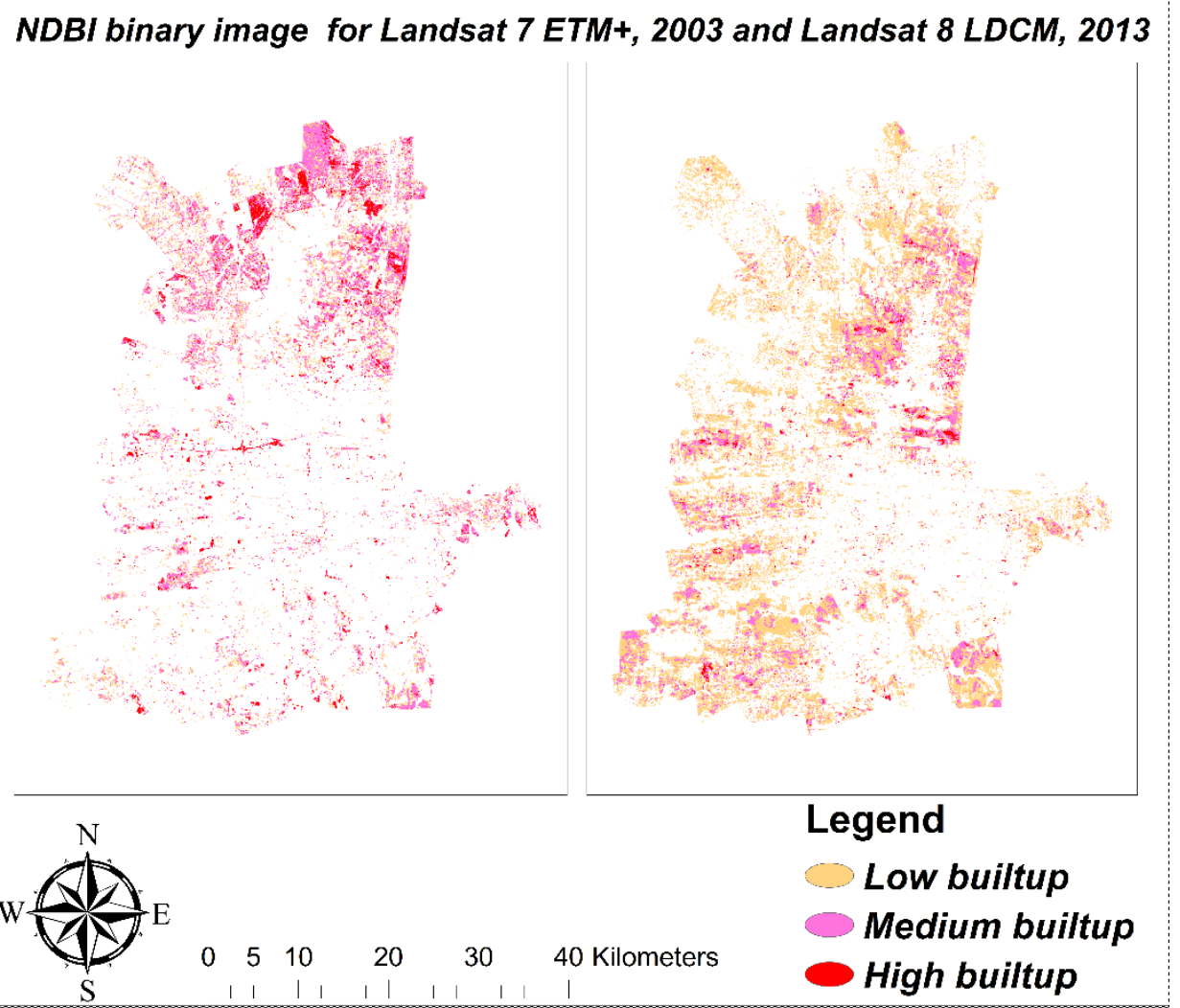

Figure 3. NDBI binary binary image for Landsat 7 ETM+ \& Landsat 8 
Figure 2 shows the NDVI binary image indicating three vegetation categories (e.g., tree plantation, cultivated lands, grasslands or parks, mixed) based on the positive NDVI threshold values from Landsat 7 ETM+2003 and Landsat 82013 within Tshwane Metropolis. Figure 3 show the NDBI binary image three built up / ISA categories (e.g., asphaltic roads, cemented floors and buildings etc.) based on the positive NDBI threshold values from Landsat 7 ETM+ 2003 and Landsat 82013 within Tshwane Metropolis. Most of these places are the central business district (CBD), industrial areas and residential areas.

Table 4. Vegetation changes from 2003 to 2013 using NDVI

\begin{tabular}{|c|c|c|c|}
\hline NDVI Landsat 7ETM+ & Area (Ha) & NDVI Landsat 8 & Area (Ha) \\
\hline Lo03 & & $\mathbf{2 0 1 3}$ & \\
\hline Low Vegetation & 42,534 & Low Vegetation & 63,474 \\
\hline Hedium Vegetation & 23,383 & Medium Vegetation & 28,624 \\
\hline & 7,174 & High Vegetation & 6,843 \\
\hline
\end{tabular}

Based on area (see Error! Reference source not found.2 and 3) it was observed that vegetation and built up / ISA has changed between the 2003 and 2013 within Tshwane metropolis. Table 4 indicates that the high vegetation areas reduced while medium and low vegetation increased from 2003 to 2013 within the metropolis. This might be due to change in overall agricultural activities or deforestation or presence of open soil or mixed with scattered vegetation.

Table 5. Impervious surface area changes from 2003 to 2013 using NDBI

\begin{tabular}{|c|c|c|c|}
\hline NDBI Landsat 7ETM+ & Area (Ha) & NDBI Landsat 8 & Area (Ha) \\
\hline Low Built up / ISA & 14,593 & Low Built up & 22,143 \\
\hline Medium Built up / ISA & 19,279 & Medium Built up & 15,343 \\
\hline High Built up / ISA & 5118 & High Built up & 3726 \\
\hline
\end{tabular}


Table 5 shows that low ISA / built up areas (i.e., outskirt) have increased whereas the medium and high ISA / built up areas (e.g., central business district, CBD) within the ten year span. This might be due to population increase which has led to land use changes in industrial areas (e.g., Pretoria West), residential areas (e.g., Pretoria North, etc.) and modifications in the CBD areas (reconstructed tall buildings within Pretoria central).

The thermal band of Landsat images not only provides a measure of the magnitude of land surface temperature, but also gives the spatial extent of the UHI effect of the entire study area (Figure 4). Based on the two land cover types (vegetation and ISA), the LST in the images ranges from $17.85-$ $40.81^{\circ} \mathrm{C}$ (Landsat $7 \mathrm{ETM}, 2003$ ) and $17.99-40.92^{\circ} \mathrm{C}$ (Landsat 8, 2013). From the image (Figure 4), the high temperature zones were observed in places like Pretoria central (CBD), Pretoria West (industrial) and residential areas such as Pretoria East and Pretoria North.

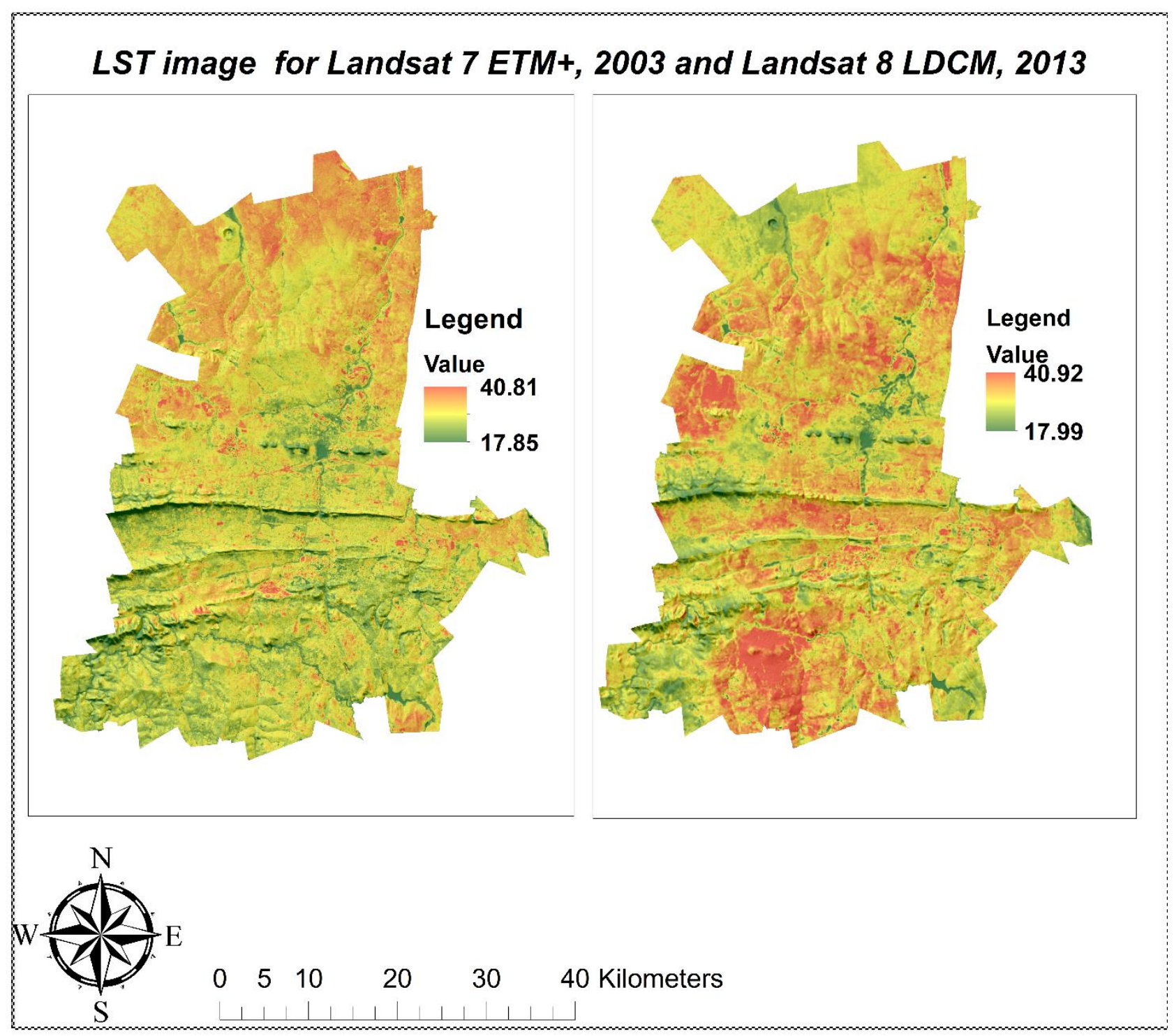

Figure 4. LST maps of the study area for Landsat 7 ETM+, 2003 and Landsat 8, 2013. 


\subsection{Statistical Test for the thematic derived binary image}

Figure 5 and 6 shows the one-way ANOVA plot of the mean surface temperature against the NDVI and NDBI derived binary images from Landsat 7 ETM + and Landsat 8 sensors respectively. This was done to compare the mean LST value of the 3 groups vegetation and ISA / built up generated in the indices images and conclude if there is a statistically significant difference among the groups.

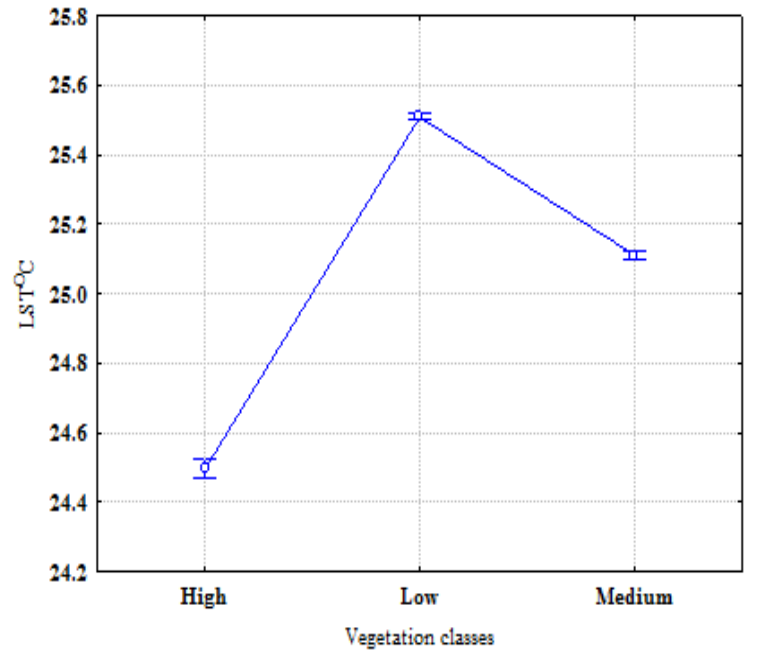

(a)

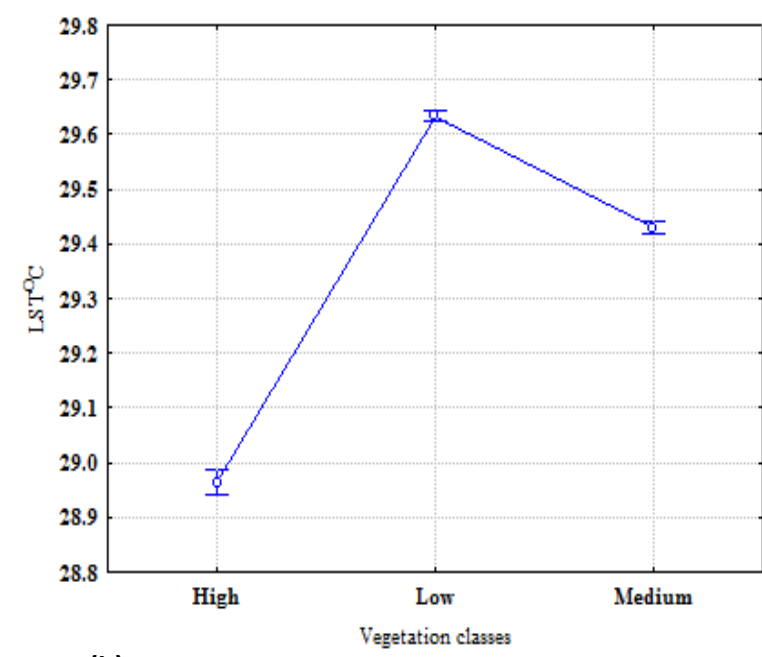

(b)

Figure 5. One-way ANOVA plot of mean surface temperature against NDVI derived vegetation groups in (a) Landsat 7 ETM +, 2003(b) Landsat 8, 2013

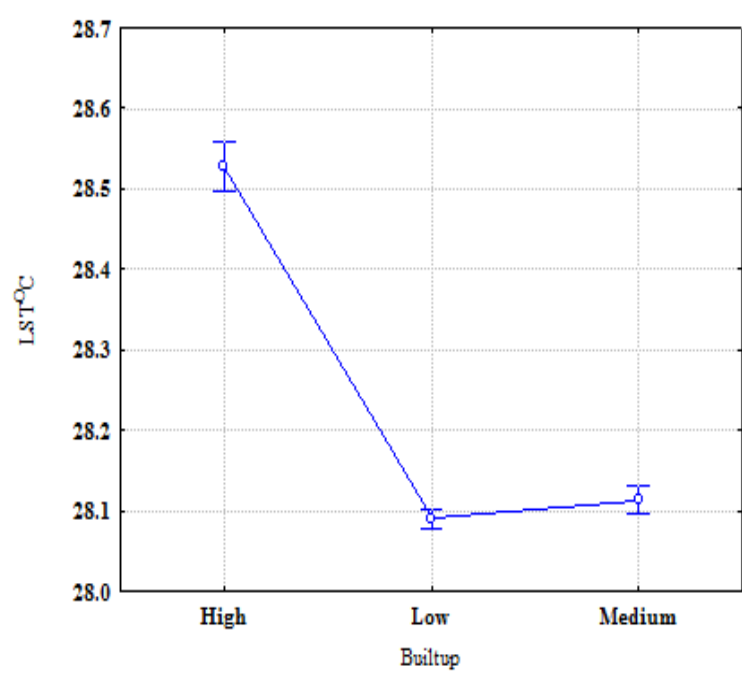

(a)

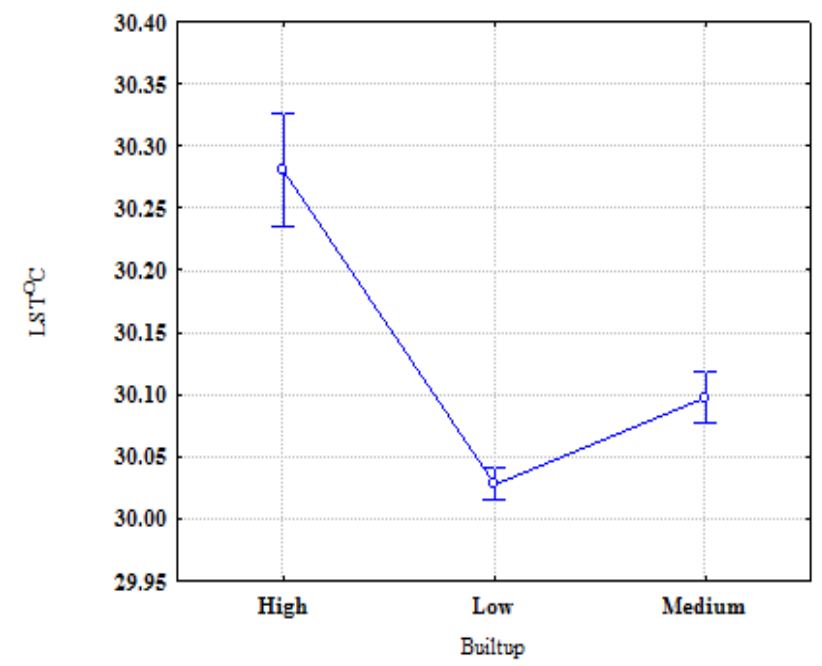

(b)

Figure 6. One-way ANOVA plot of mean surface temperature against NDBI derived built up groups in (a) Landsat 7 ETM +, 2003 (b) Landsat 8, 2013 
At 95\% significant level $(\alpha=0.05), \mathrm{H}_{\mathrm{o}}$ : Null hypothesis indicates there is no significant difference the LST values of the three groups of vegetation and built up / ISA derived in each indices derived binary images, while the $\mathrm{H}_{1}$ : Alternative hypothesis indicates there is a difference in their LST values.

From figure $5(\mathrm{a} \& \mathrm{~b}): \mathrm{H}_{\mathrm{o}}$ : high vegetation = medium vegetation = low vegetation; $\mathrm{H}_{1}$ : high vegetation $\neq$ medium vegetation $\neq$ low vegetation. Since the p-value is less than 0.05 ( $p$-value $=<2 \mathrm{e}-16)$ derived when comparing mean LST values of the vegetation groups, we reject $\mathrm{H}_{\mathrm{o}}$ null hypothesis and accept $\mathrm{H}_{1}$ the alternative hypothesis, meaning there is a significant difference in the vegetation groups derived in both Landsat 7 ETM + and Landsat 8 using NDVI. This signifies that vegetation cover within the study area has changed heterogeneously over the 10 years.

From figure 6 (a \& b): $\mathrm{H}_{\mathrm{o}}$ : high built up / ISA = medium built up / ISA = low built up / ISA; $\mathrm{H}_{1}$ : high built up / ISA $\neq$ medium built up / ISA $\neq$ low built up / ISA. Since the p-value is also less than 0.05 ( $\mathrm{p}$-value $=<2 \mathrm{e}-16$ ) derived when comparing mean LST values of the vegetation groups, we reject $\mathrm{H}_{\mathrm{o}}$ null hypothesis and accept $\mathrm{H}_{1}$ the alternative hypothesis, meaning there is a significant difference in the various built up / ISA groups derived in both Landsat 7 ETM + and Landsat 8 using NDBI due to land use or cover change.

\subsection{LST relationships to thematic indices derived vegetation and ISA / built up}

Weng (2001) indicated that the best way to understand the impact of land cover changes on LST is to investigate the links between the thermal signatures and land cover types. A sample with 1000 randomly generated points was used to investigate the relationship of LST to NDVI derived vegetation fractions and NDBI derived ISA / built up fractions from the Landsat 7 ETM +, 2003 and Landsat 8, 2013 respectively. Given a rescaled pixel size of 30m in the Landsat thermal images used (i.e., Band 6, Landsat 7 ETM + and Band 10, Landsat 8), the resultant surface temperature depend on the relative proportions of surfaces which are mostly vegetated and non - vegetated surfaces (Yuan and Bauer, 2007).

The correlation analysis was performed to investigate this relationship. The results from the linear relationship between the NDVI derived vegetation fractions in the two Landsat images in figure 7 indicated a negative relationship with the surface temperature (LST) with correlation coefficient $\mathrm{r}^{2}$ $=0.3394$ and $r^{2}=0.1095$ respectively. Figure 8 indicated a consistent positive correlation between 
the surface temperature (LST) and the NDBI derived ISA / built up fractions in both Landsat images with a correlation coefficient $\mathrm{r}^{2}=0.4619$ and 0.0816 respectively at $\mathrm{p}$-value $=<2 \mathrm{e}-16$.

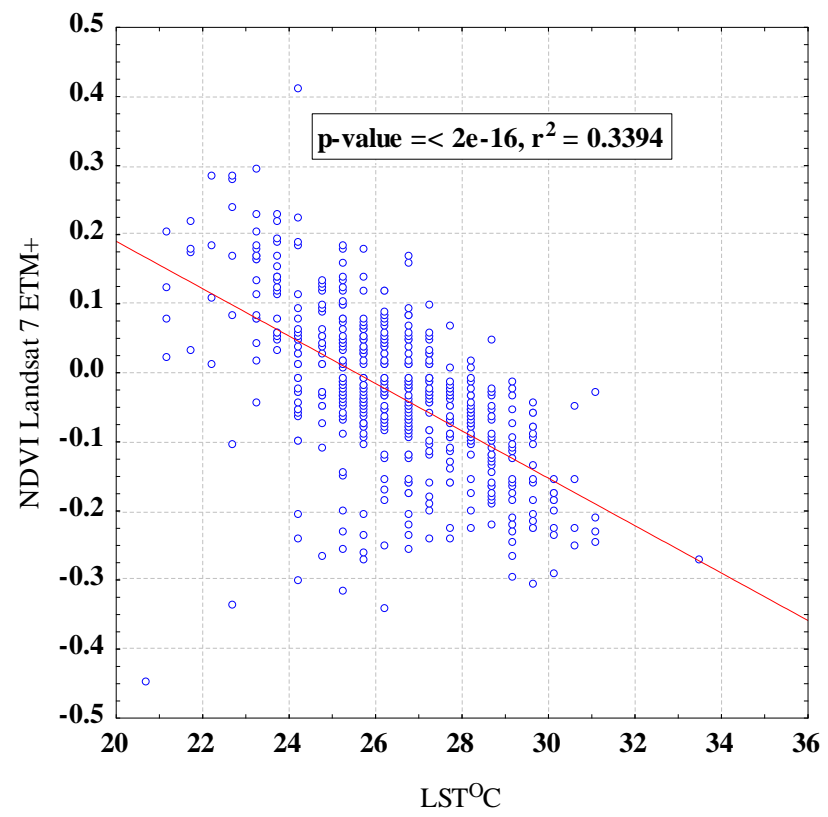

(a)

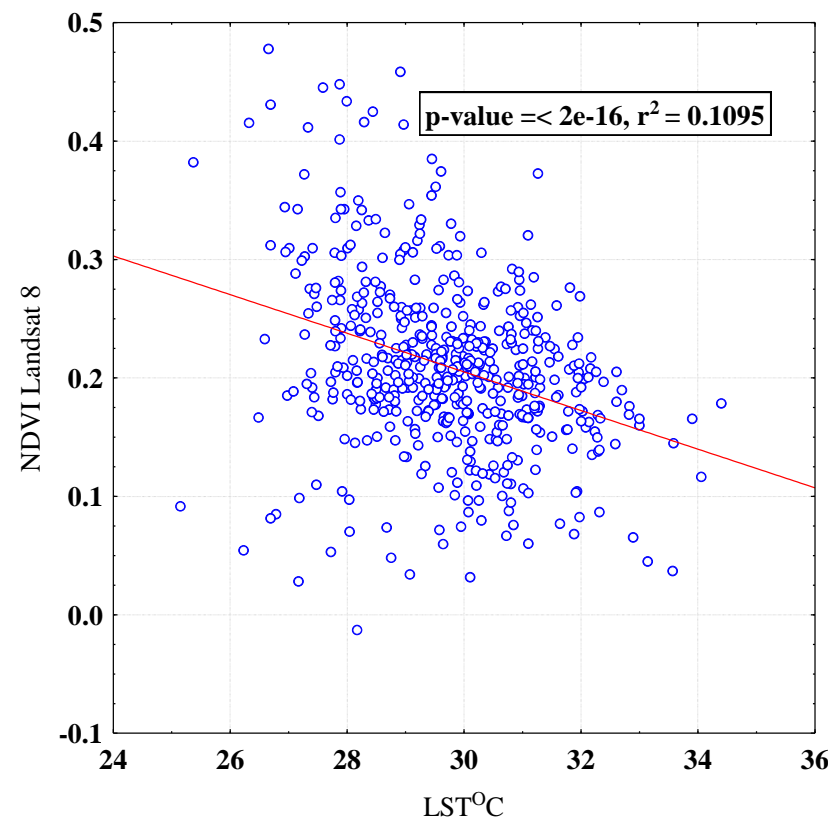

(b)

Figure 7. Scatterplot plots of NDVI binary image and mean surface temperature $\left({ }^{\circ} \mathrm{C}\right)$ LST in (a) Landsat 7 ETM +, 2003 (b) Landsat 8, 2013

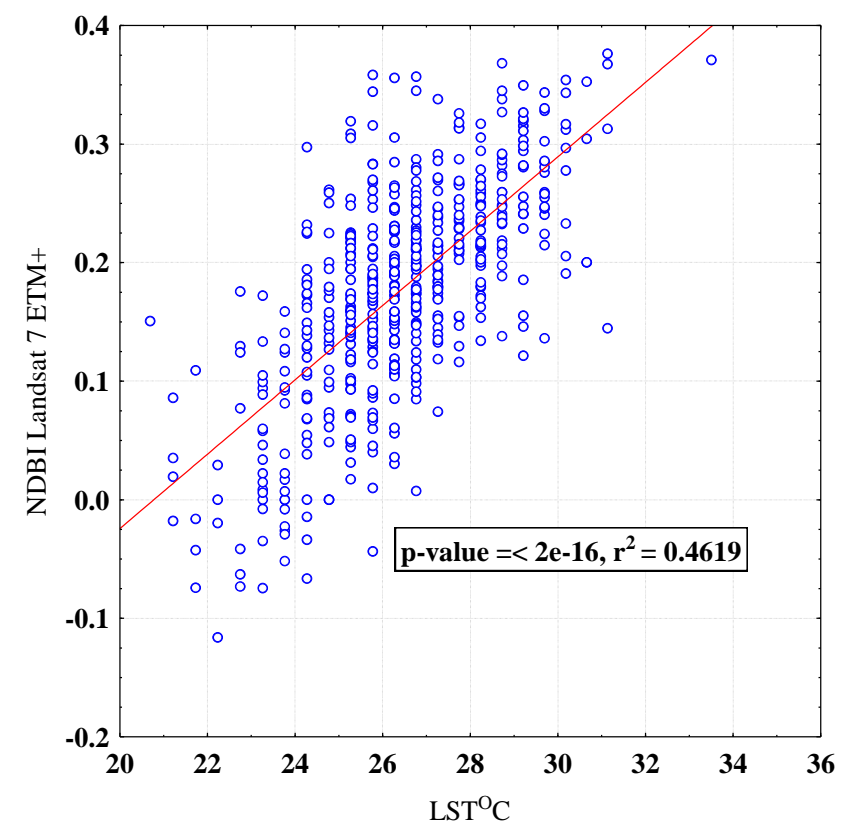

(a)

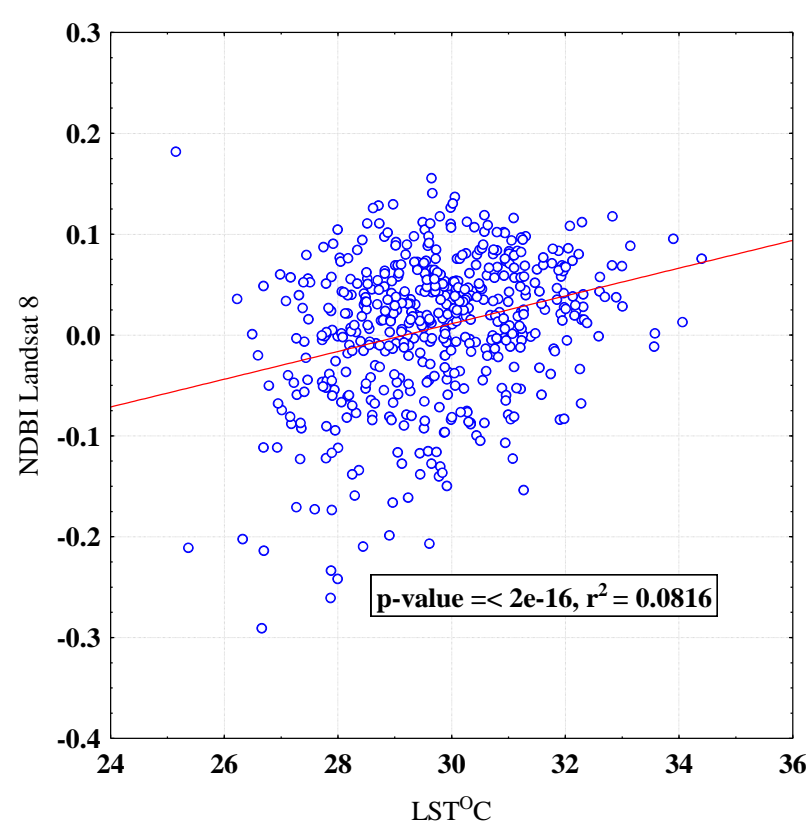

(b)

Figure 8. Scatterplot plots of NDBI binary image and mean surface temperature $\left({ }^{\circ} \mathrm{C}\right) \mathrm{LST}(\mathrm{a})$ Landsat 7 ETM +, 2003 (b) Landsat 8, 2013

In both years (figure 4), it is clearly seen that vegetation had lower surface temperature values than the ISA. These variations in the pixel temperatures may be mostly associated to impervious surface 
increase and characteristics since vegetated surfaces vary less in temperature than sunlit impervious. Some studies also point out that the cool surface temperature effect of vegetation is as a result of the light energy conservation role during photosynthesis (Bounoua et al., 2009).

\section{Discussion}

The urban expansion experienced across Tshwane Metropolitan is observed as a sign of growth and prosperity but has continuously brought about expanded infrastructure that makes use of more impervious surfaces. These changes have brought about a series of adverse impacts on the environment like ecological and hydrological disturbances of which surface temperature variation like urban heat islands is one of the major effects. An increase in manmade features such as ISA in urban areas have generally resulted in a high reflection and emission of solar radiation and greater thermal capacity and conductivity, leading to relatively higher temperatures in the urban centers compared with the surrounding rural areas.

In this study we focused on the changes in vegetation and ISA across Tshwane metropolis. From the processed Landsat images, the result clearly shows that ISA exhibits a hotter surface temperature than vegetation (figure 6). Also, the trend observed was that, pixels of places with higher surface temperature signified that vegetation was small or absent and thus showing a high chance of ISA. This was also explained through the correlation analysis performed in figure 7 and figure 8 , to investigate the relationships of LST to vegetation and impervious surface area. The measurements indicated that the ISA / built up areas had a positive linear relationship with LST (i.e., correlation coefficient $r^{2}=0.4619$ and 0.0816) and vegetation a negative linear relationship with LST (i.e., correlation coefficient $r^{2}=0.3394$ and $r^{2}=0.1095$ ). Also the contrasting quantitative effect of these two land cover changes displayed the distribution of urban heat islands scale within the study area especially around the CBD and outskirt (e.g. Centurion and City of Tshwane Rural, with increasing impervious surfaces (figure 4).

Also, the mean surface temperature from the weather stations (South African weather Station, SAWS and Pretoria Botanical Institute) was used as a point of reference to verify the accuracy of the final retrieved LST images for 2003 and 2013. From Landsat 7 ETM+ 2003, the mean pixel temperature for Pretoria Eendracht and Irene weather stations were $26.28^{\circ} \mathrm{C}$ and $26.77^{\circ} \mathrm{C}$ while the mean near surface air temperature from SAWS is $29.60{ }^{\circ} \mathrm{C}$ and $27.80{ }^{\circ} \mathrm{C}$. Hence, the LST retrieval error was $3.3^{\circ} \mathrm{C}$ and $1^{\circ} \mathrm{C}$ respectively. Similarly, with Landsat 82013 data the mean pixel temperature for the Pretoria UNISA weather station and Pretoria National Botanical Institute was 
$27.218^{\circ} \mathrm{C}$ and $28.63^{\circ} \mathrm{C}$, while the mean near surface temperature was $27.6^{\circ} \mathrm{C}$ and $29.91^{\circ} \mathrm{C}$ respectively. Thus, the LST retrieval error was $0.38^{\circ} \mathrm{C}$ and $1.3^{\circ} \mathrm{C}$ for the two stations.

Therefore, the thermal bands of Landsat 7 ETM + and Landsat 8 LCDM data employed for this study provided good results and can be used for further temperature variability analysis.

\section{Conclusion}

The study examined the relationships between the LST, thematic indices derived ISA / built up and vegetation in Tshwane metropolis. Results reveal that ISA and vegetation have experienced changes across the study area between 2003 and 2013 due to urban sprawl. Likewise, ISA proved to be a true indicator of variations in land surface temperature dynamics with a positive linear relationship between LST and ISA, whereas the relationship between LST and NDVI had a negative linear relationship. This is because the ISA / built up materials (i.e., cemented floors, old asphaltic roads etc.) emit sunlight energy while vegetation absorb sunlight energy which is used during photosynthesis. Therefore, ISA can be used as a complementary metric for surface urban heat island studies. For example, the study presented the extent of formation urban heat island scale based on impervious surface areas.

The derived surface temperature values from the satellite data (such as Landsat 7ETM + and Landsat 8) were found to be in good agreement with temperature values from the weather stations used. Therefore, the use of remote sensing data to study the variations in LST and urban landscape pattern in Tshwane metropolis shows that it offers a faster alternative and a cost effective method with the advantage of covering a large area.

Finally, the consistent information about these land cover and climate change can be used to provide vital information to multitude of social, economic and environmental policies, regulations and decision makers.

\section{Acknowledgments}

The author would like to thank the Applied Centre for Climate and Earth System Science (ACCESS) and University of Pretoria for providing the research grant to conduct this study. Much appreciation also goes to Ingrid Booysen, Lisa Nyadzua, Adeyemi Adebola Adeleke and Opeyemi Ojo for their support. 


\section{References}

Bounoua, L Safia, A Masek, J Lidard, P Imhoff, ML 2009, 'Impact of urban growth on surface climate: A case study in Oran, Algeria', Journal of applied meteorology and climatology, no.48, pp. $217-231$.

Brunsell, 2006, 'Characterization of land-surface precipitation feedback regimes with remote sensing', Remote Sensing of Environment, vol.100, pp.200-211.

Chander, G Markham, BL \& Helder, DL 2009, 'Summary of current radiometric calibration coefficients for Landsat MSS, TM, ETM+, and EO-1 ALI sensors', Remote Sensing of Environment ,vol.113, pp.893-903.

Cheng, XL, Zhao, HM Li PX \& Yin, ZY 2006, 'Remote sensing image - based analysis of the relationship between urban heat island and Land use/cover changes', Remote sensing of the Environment, vol.104, pp.133-146.

City of Tshwane Metropolitan Municipality, 2011, 'Capital Park 2008', Rovos Rail.

Deng, C \& Wu, C 2013, 'Examining the impacts of urban biophysical compositions on surface urban heat island: a spectral unmixing and thermal mixing approach', Remote Sensing of Environment, vol.131, pp.262-274.

Goddard Institute of Space Studies 2008, 'GHCN climate data, 30-year climate average', 19792008.

Huete, AR 1987, 'Soil-dependent spectral response in a developing plant canopy', Agronomy Journal, vol.79, pp.61-68.

Ifatimehin, OO Fanan, U \& Magaji, JY 2009, 'An evaluation of the effect of land use/cover change on the surface temperature of Lokoja town, Nigeria', African Journal of Environmental Science and Technology, vol.3, no 3, pp. 086-090.

Jensen, JR 2007, 'Remote Sensing of Environment: An Earth Resource Perspective',Upper Saddle River: Prentice-Hall, Inc

Jeong, JJU 2012, 'Higher temperature effects of impervious surface due to urbanization in South Berkeley, California', Impervious surface and Temperature, spring, pp.1-15.

Kasischke, ES. Goetz, S Hansen, MC Ustin, SL Ozdogan, M Woodcock, CE \& Rogan, J 2004, 'Temperate and boreal forests', In: Remote Sensing for Natural Resource Management and 
Environmental Monitoring: Manual of Remote Sensing, Vol. 4, and Edited by: Ustin, S. L. pp.147238. Hoboken, New Jersey: John Wiley and Sons, Inc. 3rd ed

Leprieur, C., Y.H. Kerr,YH S. Mastorchio,S and J. C. Meunier, JC 2000, 'Monitoring Vegetation Cover across Semi-Arid Regions: Comparison of Remote Observations from Various Scales', International Journal of Remote Sensing, vol.21, pp.281-300.

Mallick, J Kant, Y \& Bharath, BD 2008, 'Estimation of land surface temperature over Delhi using Landsat 7 ETM+', Journal of Indian Geophysics Union, vol.12, no.3, pp. 131-140.

Montgomery, MR \& Hewett, PC 2005, 'Urban health in developing countries: Household and neighborhood effects', Demography, vol.42, pp. 397- 425.

Parece, TE \& Campbell, JB 2013, 'Comparing Urban Impervious Surface Identification Using Landsat and High Resolution Aerial Photography', Remote Sensing of Environment, no.5, pp.49424960.

Pinheiro, ACT Mahoney, R Privette, JL \& Tucker, CJ 2006, 'Development of a daily long term record of NOAA-14 AVHRR land surface temperature over Africa', Remote Sensing of Environment, vol.103, pp. 153-164.

Rouse, JW Haas, RH Schell, JA \& Deering, DW 1974, ' Monitoring vegetation systems in the Great Plains with ERTS', In: Fraden, S.C., Marcanti, E.P., and Becker, M.A., (eds.), Third ERTS-1 Symposium, 10-14 Dec. 1973, NASA SP-351, Washington D.C. NASA, pp. 309-317.

United Nations, Department OF Economic \& Social Affairs, Population Division 2012, 'World Urbanization Prospects', the 2011 Revision: Highlights. New York: United Nations.

United Nations 2009, 'World Urbanization Prospects 2009, The 2009 Revision; Population Division, Department of Economic and Social Affairs', UN, New York, NY, USA, 2010.

Weng, Q 2009, 'Thermal infrared remote sensing for urban climate and environmental studies: Methods, applications, and trends', ISPRS Journal of Photogrammetry and Remote Sensing vol.64, pp.335-344.

Weng, Q 2001, 'A remote sensing-GIS evaluation of urban expansion and its impact on surface temperature in the Zhujiang Delta, China', International Journal of Remote Sensing, vol.22, pp. 1999-2014. 
South African Journal of Geomatics, Vol. 4, No. 4, November 2015

$\mathrm{Xu}, \mathrm{H} \mathrm{2010,} \mathrm{'Analysis} \mathrm{of} \mathrm{impervious} \mathrm{surfaces} \mathrm{and} \mathrm{its} \mathrm{impact} \mathrm{on} \mathrm{urban} \mathrm{heat} \mathrm{environmenta} \mathrm{using}$ Normalized Difference Impervious Surface Index (NDISI). Photogrammetric Engineering \& Remote Sensing, vol.76, pp. 557-567.

$\mathrm{Xu}, \mathrm{H}$ 2007, 'Extraction of Urban built up land features from Landsat Imagery using a thematic oriented index combination technique', Photogrammetric engineering and remote sensing, vol. 73 , no. 12 .

Yuan, F \& Bauer, ME 2007, 'Comparison of impervious surface area and normalized difference vegetation index as indicators of surface urban heat island effects in Landsat imagery', Remote Sensing of Environment vol.106, pp. 375-386,

Zhang, Y Odeh, OA \& Han, C 2009, 'Bi-temporal characterization of land surface temperature in relation to impervious surface area, NDVI and NDBI, using a sub-pixel image analysis', International Journal of Remote Sensing, vol.11, pp, 256-264.

Zha, Y Ni, S\& Yang, S 2003, 'An Effective Approach to Automatically Extract Urban Land-use from TM Imagery', Journal of Remote Sensing, vol.7, pp.37-40. 